\title{
A Biological Analysis on the Invasiveness of the Corbicula Fluminea
}

\author{
Sreyas Yeddula ${ }^{1}$, Akshay Jakkidi Reddy ${ }^{1}$, Eric Liu ${ }^{2}$ and Himanshu Wagh ${ }^{3 *}$ \\ ${ }^{1}$ California Northstate University College of Health Sciences, Rancho Cordova, USA, \\ ${ }^{2}$ University of California Los Angeles, Los Angeles, USA \\ ${ }^{3}$ California Northstate University College of Medicine, Elk Grove, USA
}

*Corresponding author: Himanshu Wagh,California Northstate University College of Medicine, Elk Grove, USA; himanshu.wagh5630@cnsu.edu

\section{ABSTRACT}

Keywords

Corbicula fluminea is an invasive species that has been observed to outcompete the Bivalves native clams at the American River located near Sacramento in the Central Valley in Cirri California. We hypothesized that $C$. Fluminea has advantages exhibited physically including utilization of filter-feeding methods and relative spacing of its cirri as Algae compared to the native American River clams. To investigate what makes the species DNA so successful, we tested $C$. Fluminea versus the native clams in algal and $E$. coli environments to predict the relative advantage of a filter feeder. In addition, we used computer programs to digitally analyze the spacing between the actual cirri, which help bivalves capture food particles, of the two species. The findings pointed towards C. Fluminea's inherent advantage in both physical and genetic traits over the native clams species which allowed it to flourish and successfully invade the American River ecosystem. However, the species' genetic findings are found through DNA analysis.

\section{INTRODUCTION}

The C. Fluminea clam served as an example of an invasive species that affects the local wildlife due to its existence being detrimental. A certain species can be categorized as invasive because it outcompetes the native species for essential resources that are critical to the survivorship of the species [1]. Because of this fact, there are much less of these essential resources such as food for the native species and this then causes a confounding effect of decreasing species diversity in the environment due to those local species being deterred elsewhere for resources. One of the most critical resources for both species of $C$. Fluminea and the native species served to be algae that grew within the water. $C$. Fluminea also is able to feed on some of the $E$. coli bacteria that lives in the soil in the river, which serves as an additional food source the $C$. Fluminea can use while competing with the native species for their only food source [2]. This then contributes to the overall population growth of the $C$. Fluminea species which will grow over time if the same feeding behavior continues. The information required to confirm the reasoning behind why the Asiatic clam is the dominant species is unknown, and further experiments would need to be conducted to fill this gap in knowledge. This lab utilizes the genetic analysis of the Asian or invasive clam to see if there are genetic differences that lead to greater efficiency when feeding to determine the identity of the clam. The main form of analysis of the species was genetic barcoding which was used to identify and compare genetic similarities and differences in the species. This form of analysis involves a series of different and complex techniques including PCR, Gel Electrophoresis, and Western blotting [3]. If the results of the experiments listed show significant discrepancies in favor of C. Fluminea, then it can be assumed that there are inherited and protein-based factors as to why the Asiatic clam reigns as the dominant species over the native species. 


\section{Research Article}

DNA barcoding is mainly based on the fact that the DNA of different species is what causes the disparities in phenotype and genotype in the first place. The barcodes for each species will be distinct for that specific species and can be looked at to look at any genetic differences [4]. This can be done by examining a short strand of DNA from a set of genes. The first step of the overall process would be to separate the DNA from the host tissue without also extracting other substances like proteins that are not DNA. The DNA pulled out will be amplified for further identification and will be done using PCR [4].

PCR, or Polymerase Chain Reaction, is a process that amplifies the size of DNA strands so that they are easier to work with in the lab setting. It is classified as an in-vitro process that uses the change in temperature, specifically heat, instead of common biological enzymes to replicate DNA [5]. The molecule that makes PCR able to work is taq polymerase, which is derived from the bacterial species of the bacterial species thermus aquaticus [3]. This species has the ability to produce polymerase that does not degrade at high temperatures(typically around 65 degrees celsius), which would further categorize the bacteria as thermophilic. The DNA molecule during PCR would need to remain at a relatively high temperature to denature or split the hydrogen bonds that are between the two strands to keep them apart due to the new nucleotides being continuously added to the template strand. Primers are also critical to the process based on where the primer anneals or recombines the strand of DNA that is replicated.

The DNA that is made using the PCR reaction is run through a gel electrophoresis experiment to separate the strands of DNA that were cut. The gel that is solidified during the process and used is made of agarose. As the name suggests, an electric current is then run through the gel, for which the positive charge of the current attracts the negative charge of the DNA due to the negatively charged phosphate groups [6]. The addition of this current eventually pulls the DNA across the gel. As this process runs, the DNA that has the same length tends to come together at different points. The bands become visible under a UV-Vis light and would be based on the distance traveled in $\mathrm{cm}$, which could then lead to the number of strands being determined.

The method used of DNA Barcoding can be used effectively to figure out the identity of the tissue that is being examined and to compare the overall gene structure of the invasive species to tell the differences between the native species on a genetic level [7]. The slight disparities can be used to indicate why one species is more effective in their environment and how this is able to outcompete the native species. Using DNA Barcoding, the genetic disparities between the two species can be looked at and compared.

The method of Western Blotting Sample Prep was used to analyze the cellular responses of the clams in extreme conditions that are present within the river. One of these conditions that commonly occurs within the American River is thermal fluctuations, and the two species can express varying heat shock proteins (HSP70) to inhibit the impact that the conditions have on their overall living conditions. Protein expression is one of the mechanisms that the species of clams use to adapt to the changing conditions of their environment and the clam species that exhibits less of these proteins is ultimately the species that is better able to adapt to the changing conditions of their environment $[8,9]$.

The SDS and Western Blotting techniques that were utilized within this lab analyzed the gill tissue of the clam samples, which was able to show the relative expression of the HSP70 proteins that are expressed under conditions of higher temperature stress . To analyze how much of the protein was present, the proteins using the SDS Page Solution and these proteins are also negatively charged which allows for them to be pulled through the gel matrix to further be analyzed based on peptide length and size [10]. The results can then be analyzed using immunodetection practices, which are able to tell exactly how much of the HSP70 protein was expressed. How varying levels of heavy metal ion concentrations affect the amount of HSP70 protein was also studied within the experiment. It was concluded that the increased amount of heavy metal ions present in the water, specifically iron sulfates, would lead to the Asiatic clam expressing more of the HSP70 protein in order to adapt to the changing environment. It was also noted that C. Fluminea may have an inherent advantage when analyzing its adaptations to the environment because it is an invasive species.

The Chemistry portion of this experiment analyzes the varying chloride concentrations in the American River and observes how that is affecting the aquatic wildlife within that specific ecosystem. Increased levels of chloride concentrations can have detrimental effects on the organisms within the ecosystem, especially the two species of clams [8]. It was hypothesized that the American River would show elevated levels of chloride ions based on past studies that have been conducted in the area, and this is having an impact on the survivability of the native species. Since $C$. Fluminea is an invasive species in the American River ecosystem, it is able to better adapt to the changing conditions of the river, which is why it is becoming the dominant species of clams. 


\section{METHODS}

\section{Subjects}

Field Collection: In order to be prepared for this experiment, clams were obtained from the American River. These clams were obtained by wearing suits that protect the researchers from any bacteria and contaminants that were in the water. After the suits were effectively put on, the samples of the clams could be obtained from various shallow areas of the river. Exactly two clams were obtained for the experiment.

Experimental Design: The clams that were obtained from the river were of the species $C$. Fluminea. This species is not naturally found in the American River and serves as an invasive species. One of the purposes of performing the experiment is also to verify that the clams that are present in abundance within the river are of the species $C$. Fluminea. To extract more information about these clams, the experiments of invertebrate feeding, bacteria detection, cirri spacing, DNA barcoding were performed.

Dissections: After the clams were obtained from the river, the samples were taken back to the lab and labeled to identify which groups had collected which samples. The clams were then opened up using various dissection tools including scissors, forceps, scalpels, and needles. One difficulty that was encountered when trying to open the clams was the fact that there are muscles that keep the clam shells from directly opening. This is why, to effectively open the clams, scalpels were used to pry open the sides of the shell where the muscles had limited effectiveness. After the clams were opened, approximately $50 \mathrm{mg}$ of the gills and mantle of the clam were cut and placed into tubes which were placed into an ice box for future experiments.

\section{Bacteria Detection}

Sample Collection: Along with the samples of clams that were obtained from the river, samples of soil and water were collected. The sample of water was obtained from the areas of the river where the clams were found. The sample of soil was obtained using a shovel to dig up a small amount from the bottom of the river.

Soil Sample Procedure: The reason the sample of soil was obtained from the river was to find the bacterial concentrations present utilizing serial dilutions. The samples would first need to be mixed to form a liquid solution. This was done by obtaining three tubes and placing the soil sample in one, and $900 \mu \mathrm{L}$ of water in the other two. The soil sample was then mixed with $1000 \mu \mathrm{L}$ of water and $100 \mu \mathrm{L}$ of this solution was transferred to tube 2 . This tube was then mixed and $100 \mu \mathrm{L}$ of this solution was transferred to tube 3 . Three agar plates were then obtained for culture. The plates were then inverted to prevent condensation and incubated overnight at $37^{\circ} \mathrm{C}$.

Water Sample Procedure: The water samples were used to determine the bacterial concentrations in the river. This was done by pipetting small amounts of river water into the 96 wells of the microplate. The side of the plate was then tapped to remove any air bubbles present in the wells. The plate was then tilted slightly to remove any excess water, which was wiped off the edge of the plate with a kim-wipe. This was mainly to ensure that there was no cross-contamination between the samples. This microplate was covered and then placed in incubation at $37^{\circ} \mathrm{C}$

Data Analysis: For the data analysis of this sample, the original cell density was calculated to find the density of the bacterial colonies present. This would help determine the number of bacterial cell colonies. Cell colonies on each plate were counted and if there were too many to where it was not distinguishable, the plate was labeled too many to count (TMTC). Then, a fluorescent light was shined over the microplate which illuminated the bacteria that was present in each sample. Wells that showcased a green color had E. coli bacteria wells that reflected a blue color had coliform bacteria. Wells that shines as a green color were indicated to have $E$. coli bacteria present.

\section{Invertebrate Feeding}

Subject Controls: The native clam species was placed in one tank while the $C$. Fluminea clam species was placed in a separate tank. This was done so that the data collected from the experiment would be for that individual species of clam with no confounding effects.

Procedure: With a 96 well plate, the first sample of water was taken and placed into the plate reader to determine the amount of chlorophyll that was present before the clams were fed with algae. The algae was stored in a separate container and this was provided by the lab technician.

With a sterile pipette, about half a pipette's worth of algae was drawn out from the container. This was then placed in the tank with the clam and mixed to spread the algae throughout the container. Every 15 minutes, three wells from the plate were filled with water from the sample. This process was repeated a total of 7 times and the microplate was placed into a plate reader to determine the amount of chlorophyll present in each plate. When experimenting with $E$. coli Bacteria, the same clams were used for the experiment. The clams from each species were once again placed in separate tanks and left unfed for 24 hours so that they would be hungry for the experiment. The $E$. 
coli samples from the previous experiment were obtained and any excess bacteria left on the top of the wells was removed. After the excess was removed, the samples were mixed to ensure an even distribution of bacteria throughout the solution. The $E$. coli was then placed into each of the tanks (about $5 \mathrm{~mL}$ ) using a sterile pipette. Every 15 minutes, a measurement of the samples was taken using a new pipette into the wells of a new microplate. This was repeated a total of 7 times and the plate was placed into a plate reader to see how much chlorophyll was present.

Data Analysis: After the plates went through the plate reader, a total of three numbers were present due to the fact that the readings of the samples were taken in threes. The three numbers from the Blank 550 were taken to find the average of the sample during a specific time interval. After obtaining the averages for each of the time intervals, the standard deviation was used to plot the error bars on the graph made for the data for each time interval.

\section{Cirri Spacing}

Sample Collection: The dissected sample gill from the Dissections experiment was used within this experiment.

Imaging: The gill samples were placed onto a slide and these were examined under a microscope. A picture was then taken in $40 \mathrm{X}$ to compare on a hemocytometer grid. The set scale option on the software was selected and a line was drawn on the grid to let the number of pixels on the grid be known. This pixel value is then converted to the picture of the gill sample. To find the exact distance between the cirri, a line was placed between the spaces in between the cirri. This process was recommended to be repeated at least 3 times and used to find the average. The standard deviations were also calculated and documented, and would later be used to form the error bars on the graphs created for cirri spacing.

Data Analysis: This experiment was done for the gill samples of both the native species clam and the C. Fluminea species clam species. The averages and standard deviations for each species were calculated as well. A bar graph was then created to compare the average values and their standard deviations. The purpose of this graph was to show the differences in the cirri spacing for each species and observe which species had greater variation. This information discovered from the graph could later be used as an indicator to why C. Fluminea is successful as an invasive species.

\section{DNA Barcoding}

Sample Preparation: The two mantles from each species of clam were utilized for this experiment. The DNA would then have to be extracted from each of these samples. To locate the DNA within the tissue, the mantle is ground up along with an added $180 \mu \mathrm{L}$ of ATL buffer. $20 \mu \mathrm{L}$ of proteinase $\mathrm{K}$ is added within each sample and mixed thoroughly. The vortexer was used to mix the samples as well as mix any of the buffers that were stuck to the sides of the tube. The samples were then placed into a heat block for $60 \mathrm{~min}$ at a temperature of $56^{\circ} \mathrm{C}$. After the samples were heated, $200 \mu \mathrm{L}$ of AL buffer was added to the tubes and vortexed for about 30 seconds. Then $200 \mu \mathrm{L}$ of ethanol was added and the tubes were vortexed for about 30 seconds. The mixtures were then transferred to spin columns that were obtained during the 60 minute heating period, and placed in a centrifuge at 8,000 RPM for 1 minute. Any flow liquid that stayed at the top of the spin column was discarded into the designated waste container. $500 \mu \mathrm{L}$ AW1 buffer was added to each column and they were spun at 8,000 RPM for 1 minute, and the flow was once again discarded. $500 \mu \mathrm{L}$ of AW2 buffer was added to each column and these were then placed into a centrifuge at 14,000 RPM for 3 minutes and any remaining flow was discarded after this. The spin columns are then centrifuged for 1 minute at 14,000 RPM to ensure that all excess fluid has been discarded. The spin columns were then placed into centrifuge tubes with an added $100 \mu \mathrm{L}$ of $\mathrm{AE}$ buffer and were incubated at room temperature for 10 minutes. After this, the samples were centrifuged at 8,000 RPM for 1 minute with the flow being saved this time as the substance that contains the DNA.

PCR: An ice box with the required tubes of solution for this lab was put together by the lab technicians and obtained at the start of the experiment. To create the PCR reaction, a master mix had to be created containing $36 \mu \mathrm{L}$ of water, $5 \mu \mathrm{L}$ of $10 \mathrm{x}$ PCR mixture, $1 \mu \mathrm{L}$ of taq polymerase, $5 \mu \mathrm{L}$ of full primer set, $2 \mu \mathrm{L}$ of template, and $1 \mu \mathrm{L}$ of dNTP mix. These were all placed within a microcentrifuge tube. We then used the 4 PCR tubes provided, $6 \mu \mathrm{L}$ of the first sample was added into tube 1 and 6 $\mu \mathrm{L}$ of the second sample into tube 2 . Tube 3 included $6 \mu \mathrm{L}$ of the positive control and tube 4 included $6 \mu \mathrm{L}$ of the negative control, which was just deionized water. All of these tubes were then mixed with the Master Mix that was divided into four equal concentrations. The tubes were then placed into a thermocycler set to $94^{\circ} \mathrm{C}$ for $2 \mathrm{~min}$. After this short interval, the cycler was set to $94^{\circ} \mathrm{C}$ for 30 seconds, followed by $60^{\circ} \mathrm{C}$ for 30 seconds, followed by $72^{\circ} \mathrm{C}$ for 30 seconds. These steps were completed at 35 cycles and were done a total of 35 times. The tubes are then placed at $7^{\circ} \mathrm{C}$ for 5 minutes and left at hold at $4^{\circ} \mathrm{C}$.

Gel Electrophoresis: Agarose gel was provided in a heated flask prior to the start of the experiment. About $25 \mathrm{~mL}$ of this liquified gel was obtained in a graduated cylinder and placed 
onto a casting tray in preparation for gel electrophoresis. Four microcentrifuge tubes were obtained along with the 4 tubes from the PCR experiment. $15 \mathrm{~mL}$ of solution from each of the PCR tubes was micro-pipetted into the microcentrifuge tubes. In each of the microcentrifuge tubes, $3 \mu \mathrm{L}$ of EZ Vision loading dye was added. $18 \mu \mathrm{L}$ of DNA size standards was placed onto lane 1 of the cooled gel using $100 \mathrm{bp}$. The second lane contained the first microcentrifuge tube and the third lane contained the solution from the second microcentrifuge tube. The fourth lane held the positive control while the fifth lane had the negative control(third and fourth microcentrifuge tubes respectively). Each lane contained approximately $18 \mu \mathrm{L}$. The plug was then plugged into the outlet and the power was turned on. The voltage was set to $1000 \mathrm{~V}$ and the gel was set to run for about $30 \mathrm{~min}$. This would lead to the first dye band making it across over halfway to about three-fourths through the gel. After the 30 minute period, the gel was carefully removed and photographed by a UV transilluminator.

Bioinformatics: A series of programs were used to sequence the DNA of the COI gene of the Asiatic clams. The first program was on Blast.com where we clicked on the "Nucleotide BLAST" button. The nucleotide sequence of the primer used in our experiment was then inputted in FASTA format into the program and then searched. The search displayed a page with a series of organisms that exhibited as a match with the sequence from the primer that was initially inputted, of which one of the organisms was selected.

After the sequence was paired with an organism, the sequencing results in the form of a chromatogram were obtained. This file was then transmitted on another program called FlinchTV. Once the nucleotide sequence was represented in the form of a color coded graph, it was trimmed of any uncalled bases that were labeled as "N". This file was then saved as ".seq" and transmitted on to the computer. The saved file was then inputted into Blast.com after which a series of organisms associated with that specific sequence came up. The first organism that appeared was $C$. Fluminea, which indicated that the trimming was successful. The file was then downloaded as a "seqdump. txt" on our computer. The FASTA files that we saved before were then uploaded onto another program. The two files came up as sequences of nucleotides, which were then compared and aligned with each other.

Data Analysis: By comparing the DNA sequences from the FASTA files and the general data, our team managed to find DNA discrepancies between the sequences. We attributed these discrepancies to mutations or any other variation that could have given the Asiatic clam a genetic advantage over their native clam species counterpart.

\section{HSP70 Protein Expression}

Sample Preparation: The acquisition of the HSP70 protein from the Asiatic clam was taken from the gill tissue. The clam tissue was acquired from the sample collection experiment and was dissected and preserved through freezing until its use in this experiment. The tissue was then exposed to the Buffer $\mathrm{K}$ and the Sample Buffer solutions respectively. Buffer K was used to deteriorate the cells and expose the components of the protein, while the components of the Sample Buffer denature the proteins and make them negatively charged.

SDS PAGE Western Blotting: The protein samples are further denatured by boiling in water for 5 minutes at $95^{\circ} \mathrm{C}$. The gel is then set up in the clamping frame and placed connected to the tetracell, ready to perform electrophoresis. The protein samples along with the molecular weight ladder are pipetted into the gel using a P20 pipette. Once the leads were connected to the gel rig, the tetracell was able to electrophorese the samples at $120 \mathrm{~V}$.

Once the samples had been run, the gel was extracted from the rig using a gel cracker. The gel is then placed in the $1 \mathrm{x}$ transfer buffer and a transfer "sandwich" is then made by putting the following components in a specific order. These components include the black side of the gel holder at the bottom to act as the anode, a pad, filter paper, gel, a PVDF membrane, more filter paper, another pad, and the clear side of the gel holder on top to act as the anode. More filter paper is placed on the top membrane and green plastic paper was used to get rid of any air bubbles. The sandwich components were then held in place as another layer of filter paper was placed on top and the sandwich was effectively closed. The sandwich was then placed into the rig with its black side facing the black side of the rig. A stir bar was added along with ice placed into the rig, which was filled with the $1 \mathrm{x}$ transfer buffer from the plastic tray used to make the sandwich. That same plastic tray was cleaned and the rig was placed inside with ice being filled on the sides. The lid was then placed on top of the cell and the power supply was attached and set to $100 \mathrm{~mA}$. This was then run for two hours with the stir plate on.

Immunodetection: For this part of the experiment, the Image J software was utilized to analyze the images of our group's specific protein sample and obtain quantitative data. The image of our specific blot was saved and dragged into the ImageJ software. The area around the first band was selected using the "Rectangular Select" tool and this band was marked using the "CTRL-1" button. The band would then be "boxed" with the mouse being on top of the border to indicate that it has been selected. The "CTRL-2" tool is then used to select the next band and this is repeated until all the bands have been 


\section{Research Article}

selected. Once all of the bands are selected the "CTRL-3" tool was used to display a histogram for each of the bands which indicated the intensity of each band. The "draw line" tool was used for each of the bands to draw a line through the top of the histogram. The "magic wand" tool was then selected and the curve of the histogram was outlined in yellow with a numerical value to represent the intensity of each band. The results were then recorded and placed in a table as a part of a figure, which included the gel image of the Western blot and a bar graph for how much each protein was expressed.
Data Analysis: Using the immunodetection procedure mentioned in the last part of Western Blotting, our team managed to effectively analyze the Western Blot and find the amount of HSP70 protein present in the Asiatic clam. It was found that the Asiatic clam, when compared to the native species, expressed a higher amount of the HSP70 protein. This means that the Asiatic clam underwent less stress when exposed to varying concentrations of heavy metal ions such as iron sulfate that were present within the water.

\section{RESULTS}

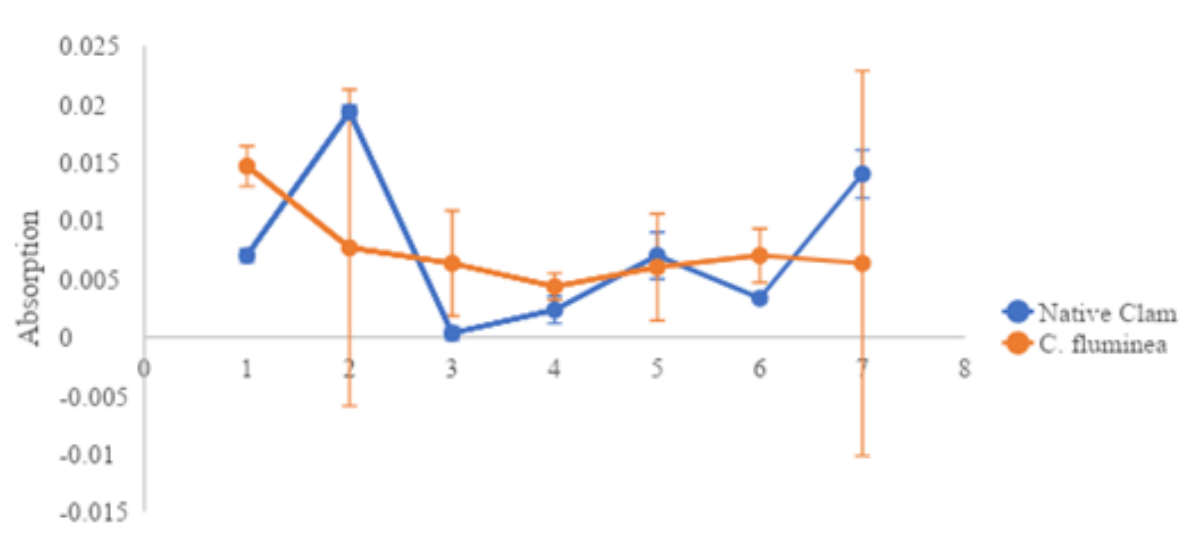

Time (15-min intervals)

Figure 1: Average Algae Filtering of Native and Invasive Clam Species

The graph above comes from our qualitative data collection. Here, the absorbance levels of algae clearance were tested in 15-minute intervals. The water was collected from tubes with our experimental clams in them to try and see how much algae the clams were siphoning from their environment. The higher the absorbance rate, the more algae that was present in the water, meaning they were not siphoning as much. The lines on top of each bar represents standard deviation for each sample.

Figure 2: Coliform Plate

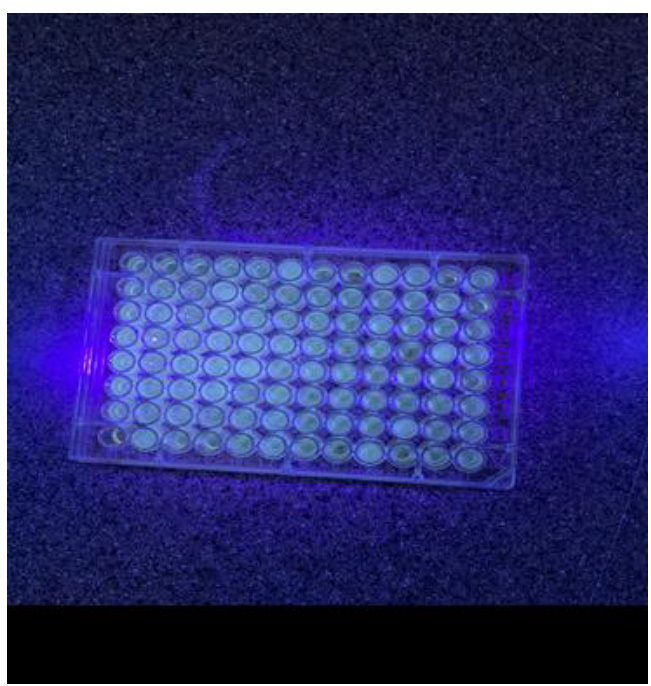

The figure above represents the coliform plate which was subjected to UV light. Fluorescent light on the plate is able to show the presence of coliforms and E. Coli within the water. It is seen that almost fifty percent of the wells are fluorescent, which shows that these are a source for C. Fluminea. 


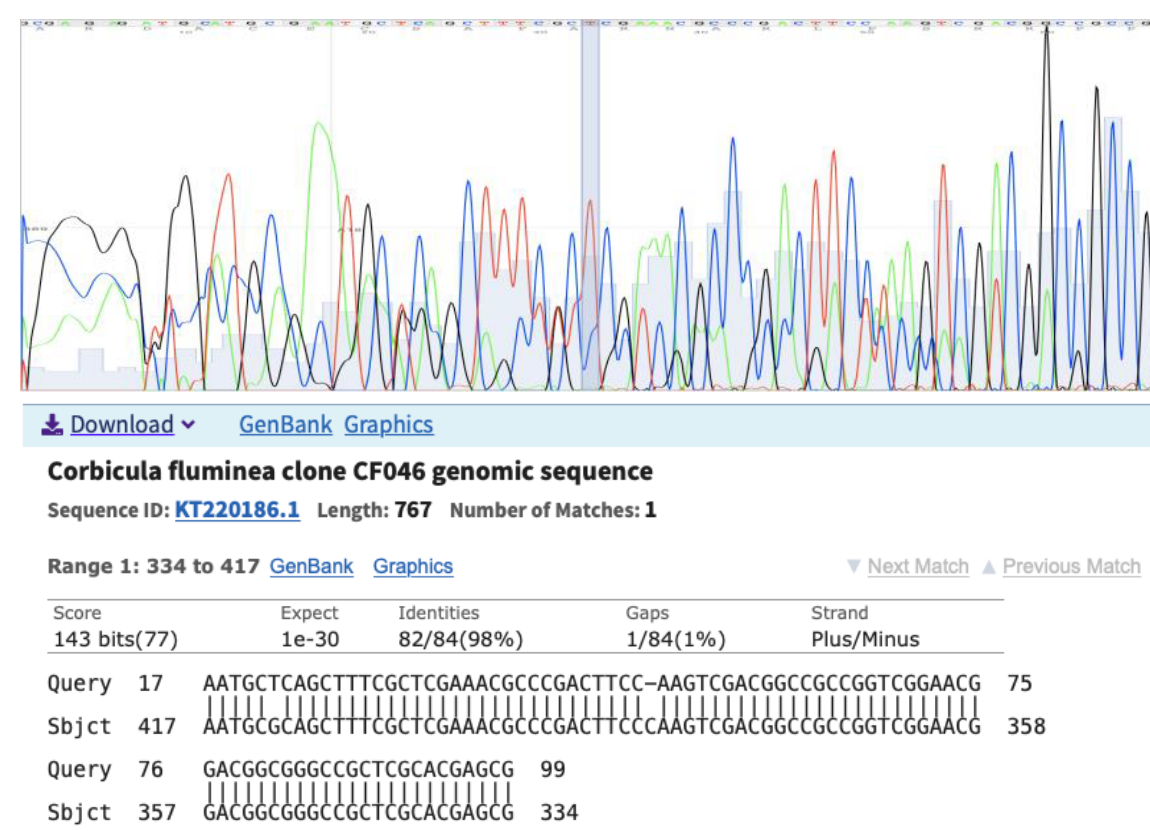

Figure 3: Sample of Corbicula Fluminea Sequencing Results

Figure 3 panel A displays the first 100 pairs from the sequencing results using 4 Peaks. Panel B displays the comparison between the DNA of our clams and the DNA of the $C$. Fluminea clam. The high match rate confirms that the clam is indeed of the species C. Fluminea.

Figure 3 panel A displays the first 100 pairs from the sequencing results using 4 Peaks. Panel B displays the comparison between the DNA of our clams and the DNA of the C. Fluminea clam. The high match rate confirms that the clam is indeed of the species C. Fluminea.

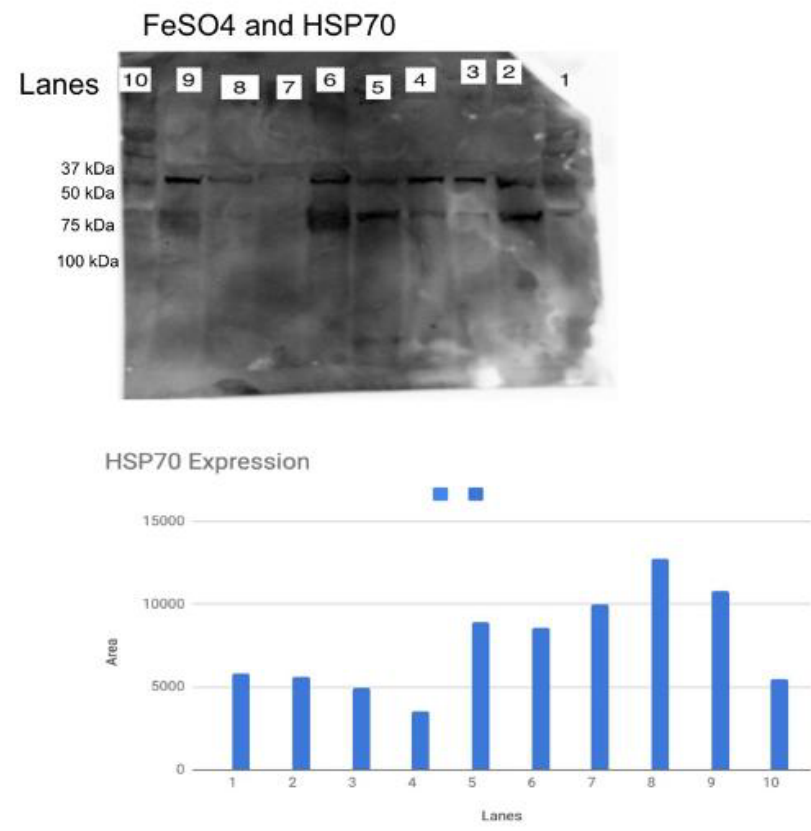

\begin{tabular}{|l|l|}
\hline Lane & Sample Loaded \\
\hline 1 & Ladder \\
\hline 2 & Positive Control \\
\hline 3 & Negative Control \\
\hline 4 & $2.5 \mathrm{mM} \mathrm{FeSO} 4$ \\
\hline 5 & $0.5 \mathrm{mM} \mathrm{FeSO} 4$ \\
\hline 6 & $0.1 \mathrm{mM}$ FeSO4 \\
\hline 7 & C. Fluminea 1 \\
\hline 8 & C. Fluminea 2 \\
\hline 9 & C. Fluminea 3 \\
\hline 10 & Ladder \\
\hline
\end{tabular}

Figure 4: Determining The Amount Of HSP70 Expression In C. Fluminea

The figure above displays the expression of the HSP70 protein in C. Fluminea utilizing three distinct panels. Panel A shows the movement of the denatured HSP70 proteins through the gel based on the size alone in which the proteins then came together in a band. Panel B displays the area of the band for each lane through a bar graph which can be translated into how much protein is present. Panel $\mathrm{C}$ represents a table which displays the contents of each of the 10 lanes. 


\section{RESULTS NARRATIVE}

The results were utilized to find the differences between the species of Asiatic clams and the invasive species of C. Fluminea. The differences in feeding rates, DNA, and expression of various proteins help each species adapt to environmental changes.

Figure 1 is taken from the first part of the experiment where the absorbance levels of the water were tested based on the amount of algae that was present within the water. If the amount of algae that was present within the water was high, meaning that the absorbance levels were high, then the clams were not siphoning out the algae from the water effectively. It is observed from the graph that the species of Asiatic clam was able to better filter out algae from the environment in comparison to the native species.

Figure 2 represents an image of a coliform plate in which each of the wells was filled with water samples from the American River. This plate was then subjected to UV light and the fluorescent light that resulted in approximately half the well represents the coliforms and $E$. coli that are present within the water. This also indicates that the species of $C$. Fluminea were able to filter approximately half of the E. coli and coliform species that was present in the samples of water.

To analyze the sequences of DNA present in the clams, the sequences were cut into 100 base pairs. Using Figure 3, the sequences were blasted using the website, Nucleotide Blast, to determine the type of species. The results of the sequence show a match to the Corbicula Fluminea clone CF046 genomic sequence. Based on the max score and the total score, it showed a complete match with an E-value of 1e-30. The sequences of the clone and the one in the experiment showcases identical DNA sequences. With these results, it can be concluded that the clams found in the American River are, in fact, Corbicula Fluminea.

Figure 4 is able to depict the expression of the HSP70 protein within the species of Asiatic clam through the use of three distinct panels. The first panel shows a gel image of the migration of the denatured HSP70 proteins in the gel, which traveled down the gel solely based on the peptide length. Panel B shows a graph that represents the amount of HSP70 protein expressed based on the band length, which indicates that the thicker the band length, the higher the stress that specific band is undergoing to express more of the protein. It can be seen when comparing Panel B to Panel C(which shows how each band was categorized) that the presence of iron sulfates in the water samples lead the Asiatic clams to produce more of the HSP70 protein in order to adapt to the changes in the environment. The band densities were also calculated using the ImageJ software, which took the area of the histograms that indicated band density, and produced a bar graph as shown in Panel B.

\section{DISCUSSION}

Through the conduction of the experiments, qualitative and quantitative conclusions can be made on why C. Fluminea is able to succeed in the American River as an invasive species. Each of the different experiments performed contribute to our overall understanding of why C. Fluminea contained particular advantages that would help them thrive in not just the American River, but in other aquatic environments throughout the United States. The experiments included the study of the feeding rates of $C$. Fluminea in comparison to the native species, DNA Barcoding to observe any genetic disparities within the Asiatic clam, and Western blotting techniques used to determine the expression of the HSP70 protein in times of environmental stress, specifically in environments with higher than normal concentrations of heavy metals.

The mechanism that both species of clams use to extract food from their environment is filter feeding [9]. The feeding rates of these clams mainly depend on how much food, E. coli or algae in this experiment, that the clams are able to extract from the water. The clams that would have a greater feeding rate would be able to filter more food from the environment, leading to an increased rate of survivability in their environment. The mechanism of filter feeding mainly depends on the spacing of the gills in the clams [8, 11-15]. The two main sources of food for $C$. Fluminea in this experiment were algae and $E$. $c o l i$. Due to the recent outbreak of $E$. coli within the American river, if the clams do indeed have greater feeding rates, the reproductive success and survivability of the species within the American river would greatly increase due to a competitive advantage that the Asiatic clam has over the native species. This claim that the Asiatic clam had the advantage as the native species was the main hypothesis throughout this experiment. It was observed that the Asiatic clam had smaller cirri spacing, meaning that the spaces between the gills that are used to filter out the food are smaller. Due to this, the E. coli bacteria that are microscopic in size could better be filtered out of the water at a higher rate than the native species. Figure 1 and Figure 2 can also be observed to show that the Asiatic clam were able to better filter out algae from the surrounding environment, as seen in Figure 1, and that the Asiatic clam had a relatively high feeding efficiency when evaluating the samples of water that they were in, as seen in Figure 2.

DNA Barcoding was performed in this experiment, and this was conducted to analyze the species by studying short fragments of their DNA, specifically from the gill samples of the Asiatic clam. Each organism contains its own DNA barcode that can 
be observed through the production of PCR amplicons from specific regions of the clam's DNA and sequencing them to identify the specific barcode of that species that distinguishes it from other species [4, 16-20]. These PCR Amplicons that were obtained from our study were run through a series of online programs to sequence the COI gene of interest. To perform this process, the sequence of nucleotides that make up the gene must be determined. DNA barcoding can also be utilized as a tool to observe the minute genetic differences between seemingly similar species such as $C$. Fluminea and the native species found in the American River. By being able to compare the DNA of the Asiatic clam to the DNA of the native clam with the distinct barcodes, the differences at the nucleotide sequence at the COI gene can be reasoned as to why the Asiatic clam is a more competitive species in the American River. Within this experiment, this was utilized to compare the clams in our own study with the standardized sequence that is found online. The DNA was compared with this standardized sequence and it was seen that any differences in DNA could be attributed to genetic mutations that gave the clams a competitive advantage over the native species. Through the conduction of this experiment, it was found that there were some genetic differences between the DNA of our own clams within the experiment and the standardized DNA found on the software that was used for comparison and this can be seen within Figure 3.

Western blotting was the second part of the experiment conducted, and this can be summarized as the process in which proteins are denatured and compared to each other based on its mass or weight and the length of its peptide [21]. This process requires the denaturing of the protein being examined with the addition of various chemicals and heat. After it is effectively denatured, it is then electrophoresed in a gel so that the various proteins can separate based on mass. In this specific experiment, Western blotting is used to find the exact amounts of HSP70 proteins within the Asiatic clam. This protein can be observed to be expressed when the clam is stressed by its surrounding environment, and this is tested in our experiment through the analysis of how much protein is expressed when concentrations of iron sulfates that are higher than average are present within the water. The more protein that is produced by the clam, the more effective that clam is in adapting to changes that are occurring in the environment [22-23]. It was concluded in this experiment that the Asiatic clam expressed higher amounts of HSP70 protein when exposed to iron sulfate and this can be observed in Panel B within Figure 4. This is able to show that the Asiatic clam is better able to adapt to environmental changes and this supports the initial hypothesis.

Accuracy of this experiment could have been increased by analyzing more samples of the species rather than the most effective sample that was made. This would lead to a greater range of results for the data obtained to be compared to. This range of data could also be applied to the differences in the $C$. Fluminea populations in different rivers, not just specifically the American River. The studies being conducted in this lab serve the purpose of allowing researchers to determine the exact reasoning and trends for the success of the invasive species. When specifically applying this concept to C. Fluminea, the different factors in the ecosystems that they choose to invade can play a role in their increased survival rate. This experiment can be further implemented outside of the lab setting through genetic testing through the use of PCR, which can distinguish markers for genetic diseases that are inherited within different families [24].

The diverse abilities of the C. Fluminea species to pedal feed, as well as filter feed are characteristics that make it a successful invasive species [25]. From observing our results, it is apparent that $C$. Fluminea are capable of multiple methods of feeding on bacterial concentrations of $E$. coli and can do so at a much higher success rate than the native species. This can further emphasize their success in the American River with the recent $E$. coli outbreak [26]. The C. Fluminea species also appear to have low genetic variability in the COI mitochondrial gene which can contribute to their overall invasiveness [24]. This increased effectiveness can have negative impacts on the ecosystems that they are present in, however [8]. The effects of C. Fluminea can also branch into economic impacts such as damaging the exteriors of boats and clogging drainage systems, costing the United States 1.5 billion dollars in losses to repair the damage per year [26]. To reduce these effects, $C$. Fluminea must further be studied and preventative measures would need to be taken to prevent any further effects that could potentially be long-lasting.

Due to the circumstances of the recent COVID-19, the last part of the experiment of Western blotting could not be done in person. Due to this, other methods of data collection had to be utilized to come to a conclusion for the study. This can be attributed as the biggest source of error, however other errors can include not comparing the differences in the DNA and the clams from the standardized sequences correctly, which would lead to inaccurate conclusions about the genetic advantages that the Asiatic clam may have over the native species.

\section{CONCLUSION}

The main purpose of the conduction of these various experiments was to closely inspect the genetic composition of the invasive clam species of $C$. Fluminea and understand how this specific species impacted the environment that they inhabited. The data gathered from this lab was able to better evaluate the environment that the clams stayed in, while the data collected from the experiments verified that the species being studied was 
indeed C. Fluminea. It was uncovered that the HSP70, or heat shock protein, had been activated at lower concentrations in this species, which indicated that there were mutations present to allow this species to outcompete the native species for resources in the American River. This therefore confirms our initial hypothesis for the experiment, which states that if the results of the experiments conducted show significant discrepancies in favor of $C$. Fluminea, then it can be assumed that there are inherited and protein-based factors as to why the Asiatic clam reigns as the dominant species over the native species. A connection can be made to the Chemistry portion of the experiment, which observed that there were increased concentrations of chloride ions in the environment, leading the Asiatic clam to better be suited for the changing environment due to its presence as the dominant species. The techniques that were utilized in the conduction of this lab are crucial to our understanding of genetically analyzing an organism and will continually be used in the field of medicine, such as the application of genetic testing to identify variations in chromosomal structure leading to genetic disorders in humans.

\section{REFERENCES}

1. Gomes C, Sousa, R, Mendes T, Borges R, Vilares P, Vasconcelos V, Guilhermino L, Antunes A. Low Genetic Diversity and High Invasion Success of Corbicula Fluminea (Bivalvia, Corbiculidae) (Müller, 1774) in Portugal. Plos One 2016, 11 (7).

2. Pigneur LM, Marescaux J, Roland K, Etoundi E, Descy JP, Doninck KV (2011) Phylogeny and androgenesis in the invasive Corbicula clams (Bivalvia, Corbiculidae) in Western Europe. BMC Evolutionary Biology 11.

3. Sousa R, Antunes C, Guilhermino L. Ecology of the Invasive Asian Clam Corbicula Fluminea (Müller, 1774) in Aquatic Ecosystems: an Overview. Annales de Limnologie - International Journal of Limnology 2008, 44 (2), 85-94.

4. Kress WJ, Erickson DL. DNA barcodes: genes, genomics, and bioinformatics. Proc Natl Acad Sci U S A. 2008 Feb 26;105(8):2761-2. doi: 10.1073/pnas.0800476105.

5. Garibyan L, Avashia N. Polymerase chain reaction. J Invest Dermatol. 2013 Mar;133(3):1-4. doi: 10.1038/jid.2013.1. PMID: 23399825; PMCID: PMC4102308.

6. Lee PY, Costumbrado J, Hsu CY, Kim YH. Agarose gel electrophoresis for the separation of DNA fragments. J Vis Exp. 2012 Apr 20;(62):3923. doi: 10.3791/3923. PMID: 22546956; PMCID: PMC4846332.

7. Kress WJ, Erickson DL. DNA barcodes: methods and protocols. Methods Mol Biol. 2012;858:3-8. doi: 10.1007/978-1-61779591-6_1. PMID: 22684949.

8. Way CM, Hornbach DJ, Miller-Way CA, Payne BS, Miller AC.

9. Dynamics of Filter Feeding in Corbicula Fluminea (Bivalvia: Corbiculidae). Canadian Journal of Zoology 1990, 68 (1), 115-120.
10. Werner S, Rothhaupt KO. Effects of the Invasive BivalveCorbicula Flumineaon Settling Juveniles and Other Benthic Taxa. Journal of the North American Benthological Society 2007, 26 (4), 673-680.

11. Smith BJ. SDS Polyacrylamide Gel Electrophoresis of Proteins. Methods Mol Biol. 1984;1:41-55. doi: 10.1385/0-89603-0628:41. PMID: 20512673.

12. Sunil A, Shaheed G, Reddy AJ, Nawathey N, Brahmbhatt H: A review on the role of ethylenediaminetetraacetic acid (EDTA) in the treatment and understanding of psoriasis. Cureus. 2021, 16:16424. 10.7759/cureus.16424

13. Reddy AJ, Tak N, Martel JB: Case study of endogenous streptococcal endophthalmitis in the critical care setting. Cureus. 2021, 5:16192. 10.7759/cureus.16192

14. Wagh H, Reddy AJ: A comparison of DASH scores resulting from different treatment options for the intra-articular distal radius fracture in the geriatric population. Appl Cell Biol. 2021, 9:18-23. 10.53043/2320-1991.acb90004

15. Tak N, Reddy A J, Martel J, et al. Clinical Wide-Field Retinal Image Deep Learning Classification of Exudative and NonExudative Age-Related Macular Degeneration. Cureus. 13:17579. 10.7759/cureus. 17579

16. Tak N, Wagh P, Sandhu S, Reddy A, Wagh H. A quantitative analysis on the effect of varying nitrate concentrations on $\mathrm{pH}$ levels on the growth of algae. Appl Cell Biol. 2021, 9:24-28. 10.53043/2320-1991.acb90005

17. Reddy AJ, Martel JB: Deep neural network learning for detection and grading of diabetic retinopathy. Appl Cell. 2020, 8:67-73. 10.53043/2320-1991.acb90001

18. Sandhu S, Sandhu A, Reddy AJ, et al. An Investigative Study into the C. flumenia and its Interactions with its Surrounding Ecosystem. Appl Cell Biol. 2021, 9:33-42. 10.53043/2320-1991. acb90007

19. Reddy AJ, Tak N, Nawathey N, et al. (October 11, 2021) Treatment of a Rare Case of Orbital Necrotizing Fasciitis Utilizing Negative Pressure Wound Therapy. Cureus. 13:18682. 10.7759/cureus. 18682

20. Shaheed G, Manjooran AP, Reddy AJ, Nawathey N, Habib $\mathrm{S}$, Brahmbhatt H. Low-Dose Naltrexone Co-Treatment in the Prevention of Opioid-Induced Hyperalgesia: Cureus. 2021, 2:17667. 10.7759/cureus.17667. PMID: 34646707 PMCID: PMC8487298

21. Senthilraja V, Lou E, Nakka A, et al. Exploring Drug and AntibodyBased Treatment Options for Creutzfeldt-Jakob Disease. Appl Cell Biol. 2021:43-48. 10.53043/2320-1991.acb90008

22. Mahmood T, Yang PC. Western blot: technique, theory, and trouble shooting. N Am J Med Sci. 2012 Sep;4(9):429-34. doi: 10.4103/1947-2714.100998.

23. Falfushynska HI, Phan T, Sokolova IM. Long-Term Acclimation to Different Thermal Regimes Affects Molecular Responses to Heat Stress in a Freshwater Clam Corbicula Fluminea. Sci Rep. 2016 Dec 20;6:39476. doi: 10.1038/srep39476. 
24. Ingeborg Werner David E Hinton. Field validation of hsp70 stress proteins as biomarkers in Asian clam (Potamocorbula amurensis): is downregulation an indicator of stress? Biomarkers 1999;4(6):473-84. doi: 10.1080/135475099230633.

25. Serdar S. A New Bivalvia Species in the West Aegean; Asian Clam Corbicula Fluminea (Müller, 1774). Ege Journal of Fisheries and Aquatic Sciences 2016, 33 (4), 329-334.
26. Elliott P, Ermgassen PZ. The Asian Clam (Corbicula Fluminea) in the River Thames, London, England. Aquatic Invasions 2008, $3(1), 54-60$.

27. Rajagopal S, Gelde GVD, Vaate ABD. Reproductive Biology of the Asiatic Clams Corbicula Fluminalis and Corbicula Fluminea in the River Rhine. Fundamental and Applied Limnology 2000, 149 (3), 403-420. 